\title{
Lithium Zinc Chloride Nanoparticles by Simple Co-Precipitation Method
}

\author{
Kathoon Sanofer $\mathbf{S}^{1}$, Madhumitha $\mathbf{B}^{1}$, Ponsurya $\mathbf{P}^{2}$, Abbas Shahul Hameed BH ${ }^{3}$, Mikila Vaahini $K^{4}$, Sekar $\mathbf{N}^{6}, \mathbf{N a g a r a n i}^{5}$ and Ayeshamariam $\mathbf{A}^{6^{*}}$ \\ ${ }^{1}$ Department of Instrumentation Control, St. Joseph's College of Engineering, Chennai-119, India \\ ${ }^{2}$ Department of Mechanical Engineering, Loyola ICAM College of Engineering and Technology, Nungambakkam, Chennai-34, India \\ ${ }^{3}$ Department of Mechanical Engineering, SMR East Coast College of Engineering and Technology, Somanathapattinam, Thanjavur District, 614 612, India \\ ${ }^{4}$ Department of Electrical and Electronics Engineering, St. Joseph's College of Engineering, Chennai-119, India \\ ${ }^{5}$ Department of Physics, Sree Meenakshi Government Arts College for Women, Madurai, 625002, India \\ ${ }^{6}$ Department of Physics, Khadir Mohideen College, Adirampattinam, 614701, India
}

*Corresponding author: Ayeshamariam A, Department of Physics, Khadir Mohideen College, Adirampattinam, 614701, India, Tel: +91-9486738806; E-mail: aismma786@gmail.com

Received Date: August 17, 2018; Accepted Date: August 24, 2018; Published Date: August 31, 2018

Copyright: () 2018 Kathoon Sanofer S, et al. This is an open-access article distributed under the terms of the Creative Commons Attribution License, which permits unrestricted use, distribution, and reproduction in any medium, provided the original author and source are credited.

\begin{abstract}
Lithium zinc chloride nanoparticles were prepared by simple co-precipitation method and characterized by using X-ray Diffractometer to find the crystal structure and its size. Morphological studies confirm the shape and agglomerations of individual nanoparticles. Optical photoluminescence studies gives its emission and excitation wavelengths. Further this particle will be used to prepare battery device of energy storing applications.
\end{abstract}

Keywords: $\mathrm{LiZnCl}_{4}$; Co precipitation; XRD; Optical studies

\section{Introduction}

Nanoparticulate electrodes, such as $\mathrm{Li}_{2} \mathrm{ZnCl}_{4}$, have unique advantages over their microparticulate counterparts for the applications in Li-ion batteries because of the shortened diffusion path and access to nonequilibrium routes for fast $\mathrm{Li}$ incorporation, thus radically boosting power density of the electrodes [1-3]. Li intercalation occurs locally in a single nanoparticles of such materials remains unresolved because real-time observation at such a fine scale is still lacking which was well agreement with the JCPDS file number 86-1806. Many researchers reported visualization of local $\mathrm{Li}$ intercalation via solid-solution transformation in individual $\mathrm{Li}_{2} \mathrm{ZnCl}_{4}$ nanoparticles, enabled by probing sub-angstrom changes in the lattice spacing in situ. The real-time observation reveals inhomogeneous intercalation, accompanied with an unexpected reversal of $\mathrm{Li}$ concentration at the nanometer scale. The origin of the reversal phenomenon is elucidated through phase-field simulations, and it is attributed to the presence of structurally different regions that have distinct chemical potential functions. The findings from this study provide a simple perspective on the structural and morphological properties of synthesized $\mathrm{Li}_{2} \mathrm{ZnCl}_{4}$ nanoparticles by using sol-gel method [4-6].

\section{Materials and Methods}

For synthesis of nano composites using analytical grade I molar solution in $25 \mathrm{ml}$ of Lithium chloride MW (42.394 gm/mol) $(1.0599$ gm) with 0.05 molar solution of Zinc chloride Molar mass (136.286 g/ mol) $(0.17 \mathrm{gm})$ and $\mathrm{H}_{2} \mathrm{O}_{2}$ liquid $(10 \mathrm{vol} \%)$ was stirred with total volume of $25 \mathrm{ml}$ deionised water without further purification. By using magnetic stirrer the above solution was stirred for one hr continuously. Milk white solution was placed on the hot plate and raise the temperature above $100^{\circ} \mathrm{C}$ until we get the fine powder. It is very simple co-precipitation method to prepare the particles. Then the prepared nano composites were oven dried at $60^{\circ} \mathrm{C}$ for 2 hours and finally annealed to the temperatures of $200^{\circ} \mathrm{C}$ for continuous 2 hours under static air atmosphere $[7,8]$. The as prepared and annealed nano composites were taken for further characterisation.

\section{Characterization}

The nanoparticles confirmation were carried out by powder X-ray diffraction (XRD) X-ray diffractometer (XRD) with monochromation $\mathrm{CuKa}$ target $\left(1.5406 \mathrm{~A}^{\circ}\right)$ at a scan rate of $20 / \mathrm{min}$. Scanning electron microscope (SEM) work on the calcined powders were performed under Scanning Electron Microscope Cambridge 53400N. The photoluminescence (PL) spectra were obtained from fluorospectrophotometer (Cary Eclipse) by using $280 \mathrm{~nm}$ line of Xe lamp as excitation source.

\section{Results and Discussion}

\section{Structural studies (XRD)}

The structure of the crystallites of the thin films developed is to be studied to assess whether the films could be used for the intended applications. The X-ray Diffraction (XRD) technique is a very powerful tool for the crystal structure determination. X-rays are a form of electromagnetic radiation, which can be diffracted by the atom bearing planes of a crystal. Using X-ray diffraction, information about the crystal structure can be obtained from the positions and intensities of the diffracted beams. Taking that the scattering centers (atoms) are located in a set of crystal planes whose directional properties are described by the Miller indices hkl, the distance between the planes $\left(\mathrm{d}_{\mathrm{hkl}}\right)$ can be related to the scattering angle $\left(\theta_{\mathrm{hkl}}\right)$ between the planes and the incoming beam, by the Bragg equation [9].

\section{$2 \mathrm{dhkl} \sin \theta \mathrm{hkl}=\mathrm{n} \lambda$}

Where $\lambda$ is the wavelength of the $\mathrm{X}$-rays and $\mathrm{n}$ is the order of diffraction. For diffraction it is also necessary that $\theta_{\mathrm{hkl}}$ is the angle 
Citation: Kathoon Sanofer S, Madhumitha B, Ponsurya P, Abbas Shahul Hameed BH, Mikila Vaahini K, et al. (2018) Lithium Zinc Chloride Nanoparticles by Simple Co-Precipitation Method. J Bioengineer \& Biomedical Sci 8: 254. doi:10.4172/2155-9538.1000254

Page 2 of 3

between the diffracted beam and the planes. Further the incoming and diffracted beams must be in a plane normal to the set of diffracting planes. Once the diffraction angles ' $\theta$ ' are measured, the corresponding d's and [hkl] values can be fixed. In the geometry of the practical diffractometers, only $2 \theta$ can be measured. So from the photographed $\mathrm{X}$-ray pattern, the $2 \theta$ values and the intensity of the maxima can be found and a plot between $2 \theta$ and intensity made for studies. The modern X-ray diffractometers (XRD) make use of a built in computer, which is programmed to give directly the print out of a plot of $2 \theta$ versus intensity of the diffracted beam (Figure 1). The crystallite size was determined by means of the X-ray line broadening method using the Scherer equation.

$$
\mathrm{D}=\frac{0.94 \lambda}{\beta \operatorname{Cos} \theta}
$$

Where, $\mathrm{D}$, the crystallite size, $\lambda$, the wavelength of the radiation ( $1.5406 \AA$ for $\mathrm{Cu}-\mathrm{Ka}$ radiation), $\beta$, the corrected peak width at halfmaximum intensity, and $\theta$, the peak position.

The calculated average crystallite size and its lattice parameters were tabulated in Tables 1 and 2 for the as-prepared sample and Tables 3 and 4 for $200^{\circ}$, for $\mathrm{Li}_{2} \mathrm{ZnCl}_{4}$ NPS which reveals the nanocrystalline size of the prepared powder. From this value, the specific surface area was calculated assuming the presence of spherical particles, by means of the equation.

$$
S=\frac{6}{\rho D}
$$

Where, $\rho$, the calculated density of the material was nearly 2.536 $\mathrm{g} / \mathrm{cm}^{3}$ and $\mathrm{D}$, the crystallite size of the sample. It has orthorhombic primitive lattices. From the Tables 1-4 the surface area of the particle 420 diffraction planes are different [10].

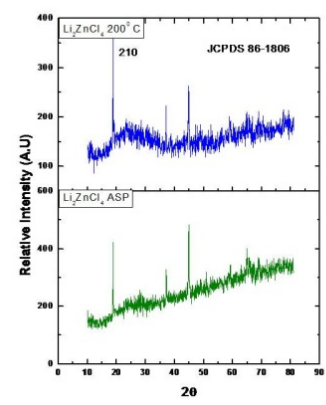

Figure 1: $\mathrm{XRD}$ analysis of $\mathrm{Li}_{2} \mathrm{ZnCl}_{4}$ for the asprepared and $200^{\circ} \mathrm{C}$ samples.

\begin{tabular}{|l|l|l|l|l|l|l|}
\hline $\mathbf{2 \theta}$ (obs) & $\begin{array}{l}\mathbf{2 \Theta} \text { (JCPDS) } \\
\mathbf{8 6 - 1 8 0 6}\end{array}$ & FWHM & dobs & $\begin{array}{l}\text { Dexp } \\
\text { (JCPDS) } \\
\mathbf{8 6 - 1 8 0 6}\end{array}$ & hkl & S=6/pD \\
\hline 18.7955 & 18.314 & 0.1476 & 4.8404 & 4.7257 & 210 & 26 \\
\hline 37.0806 & 37.118 & 0.1968 & 2.4202 & 2.4275 & 420 & 38 \\
\hline 44.8714 & 44.873 & 0.1968 & 2.0182 & 2.0222 & 331 & 31 \\
\hline
\end{tabular}

Table 1: Structural properties or the sample 5\% concentration of $\mathrm{Zn}$ with Lithiumchloride aspreapred powdered particles.

\begin{tabular}{|l|l|l|l|l|l||}
\hline hkl & $\begin{array}{c}\text { Crystal Size }(n m) \\
D=\frac{0.94 \lambda}{\beta \operatorname{Cos} \theta}\end{array}$ & \multicolumn{5}{|l||}{ Lattice parameter $\left(\mathbf{A}^{\circ}\right)$} \\
\hline 210 & 54.8 & A & b & c & \\
\hline 420 & 42.6 & 12.77 & 7.417 & 6.111 & JCPDS \\
\hline 331 & 43.8 & 12.009 & 7.125 & 6.023 & Calculated \\
\hline
\end{tabular}

Table 2: Crystal size and its lattice parameters for the sample 5\% concentration of $\mathrm{Zn}$ with Lithium chloride for the as-prepared sample.

\begin{tabular}{|l|l|l|l|l|l|}
\hline $2 \Theta$ (obs) & $\begin{array}{l}\mathbf{2}(\text { (JCPDS) } \\
\mathbf{8 6 - 1 8 0 6}\end{array}$ & FWHM & dobs & $\begin{array}{l}\text { dexp } \\
\text { (JCPDS) } \\
\mathbf{8 6 - 1 8 0 6}\end{array}$ & $\mathrm{S}=\frac{6}{\rho \mathrm{D}}$ \\
\hline 18.778 & 18.314 & 0.0984 & 4.7257 & 4.8404 & 63 \\
\hline 37.0334 & 37.118 & 0.1476 & 2.4275 & 2.4202 & 56 \\
\hline 44.8192 & 44.873 & 0.2460 & 2.0222 & 2.0182 & 58 \\
\hline
\end{tabular}

Table 3: Structural properties for the sample 5\% concentration of $\mathrm{Zn}$ with lithium chloride at $200^{\circ} \mathrm{C}$.

\begin{tabular}{|l|l|l|l|l|l|}
\hline hkl & Crystal Size & \multicolumn{4}{|l|}{ Lattice parameter $\left(\mathbf{A}^{\circ}\right)$} \\
\hline 210 & 81.21 & A & b & C & \\
\hline 420 & 56.78 & 12.77 & 7.417 & 6.111 & JCPDS \\
\hline 331 & 34.95 & 12.059 & 7.258 & 6.009 & Calculated \\
\hline
\end{tabular}

Table 4: Crystal size and lattice parameters values for the sample 5\% concentration of $\mathrm{Zn}$ with Lithiumchloride at $200^{\circ} \mathrm{C}$.

\section{SEM Analysis of $\mathrm{Li}_{2} \mathrm{ZnCl}_{4}$}

Figure $2 \mathrm{a}$ and $2 \mathrm{~b}$ shows the surface morphology of $\mathrm{Li}_{2} \mathrm{ZnCl}_{4}$ powdered particles prepared at proportions of (9:1) at room temperature for 1.0 Molar solution concentrations were observed. From these images it can be seen that the grain sizes of the powdered particles are not uniform. Therefore average grain sizes were estimated from different grains within the powder and to be about $0.8 \mu \mathrm{m}$ to 1.0 $\mu \mathrm{m}$. It is also seen that the edge texture of the particles become sharper and the grain boundaries become clearer by increasing the $\mathrm{Zn}$ content. It exhibits spherically shaped secondary particles consisting of primary nanospheres of approximately $0.8 \mu \mathrm{m}$ to $1.0 \mu \mathrm{m}$ [11].

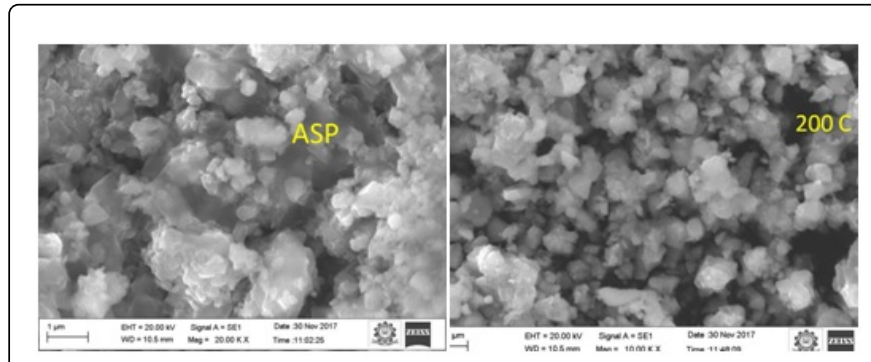

Figure 2a and 2b: Scanning Electron Microscopy and its analysis for ASP and $200^{\circ} \mathrm{C}$. 
Citation: Kathoon Sanofer S, Madhumitha B, Ponsurya P, Abbas Shahul Hameed BH, Mikila Vaahini K, et al. (2018) Lithium Zinc Chloride Nanoparticles by Simple Co-Precipitation Method. J Bioengineer \& Biomedical Sci 8: 254. doi:10.4172/2155-9538.1000254

Page 3 of 3

\section{Photoluminescence studies}

The room temperature photo luminescent spectra of as prepared sample $\mathrm{Li}_{2} \mathrm{ZnCl}_{4}$ nano particles were studied using UV-excitation $(\lambda=370 \mathrm{~nm})$.The data were recorded in the region of $350 \mathrm{~nm}-550 \mathrm{~nm}$ and spectra were shown in Figure $3 . \mathrm{Li}_{2} \mathrm{ZnCl}_{4}$ nano particles in the percentage of 0.05 equally were doped with $\mathrm{Zn}$ of $99 \%$ were dissolved in ethanol containing a weak UV emission at $493 \mathrm{~nm}(2.6 \mathrm{eV})$ and relatively intense emission at $532 \mathrm{~nm}(2.33 \mathrm{eV})$. The weak ultra violet emission at $494 \mathrm{~nm}$ is attributed to band edge emission which is associated with in the vacancy related to defects emission for $200^{\circ} \mathrm{C}$ sample. The medium intensity of other two peaks was due to the enhancement of non radioactive recombination process which occurred for the annealing samples [12].

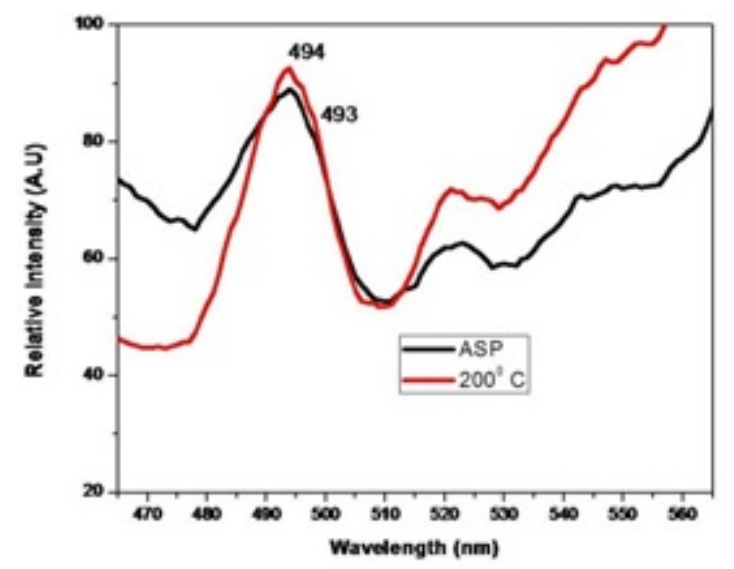

Figure 3: Photoluminescence analysis of $\mathrm{Li}_{2} \mathrm{ZnCl}_{4} \mathrm{NPs}$ at ASP and at $200^{\circ} \mathrm{C}$.

\section{Conclusion}

First time by simple co-precipitaton method $\mathrm{Li}_{2} \mathrm{ZnCl}_{4}$ NPs were prepared. The crystallite sizes for ASP and $200^{\circ} \mathrm{C}$ particles were calculated nearly equal to $47.06 \mathrm{~nm}$ and $57.64 \mathrm{~nm}$ the lattice parameter and dislocation densities were under the very small regimes. This is due to the small crystal size of the prepared particles. Due to its agglomeration the particle size becomes larger in $\mu \mathrm{m}$ shown in its morphological studies of Scanning Electron Microscopy. The PL analysis emission wavelength in $\mathrm{nm}$ well matched with the calculated prepared molar ratio of the source materials.

\section{References}

1. Nagatomo T, Maruta Y, Omoto O (1990) Electrical and optical properties of vacuum-evaporated indium-tin oxide films with high electron mobility. Thin Solid Films 192: 17-25.

2. Fallah HR, Ghasemi M, Hassanzadeh A, Steki H (2007) The effect of annealing on structural, electrical and optical properties of nanostructured ITO films prepared by e-beam evaporation. Mater Res Bull 42: 487-496.

3. Younggun H, Donghwan K, Jun-Sik C, Seok-Keun K (2005) Ultraflat indium tin oxide films prepared by ion beam sputtering. Thin Solid Films 473: 218-223.

4. Benamar E, Rami M, Messaudi C, Sayah D, Ennaoui A (1999) Structural, optical and electrical properties of indium tin oxide thin films prepared by spray pyrolysis. Solar Energy Materials and Solar Cells 56: 125-139.

5. Ellmer K (2000) Magnetron sputtering of transparent conductive zinc oxide: relation between the sputtering parameters and the electronic properties. J Phys D Appl Phys 33:R17-R32.

6. Kiyotaka W, Makoto K, Adachi (2004) Thin Film Materials Technology Sputtering of Compound Materials. (1stedn), William Andrew, USA.

7. Ellerby LM, Nishida CR, Nishida F, Yamanaka SA, Dunn B, et al. (1992) Encapsulation of proteins in transparent porous silicate glasses prepared by the sol-gel method. Science 255: 1113-1115.

8. Jianbo L, Yong F, Hua P, Meiqiang F, Liangliang W, et al. (2012) Controllable hydrogen generation performance from $\mathrm{Al} / \mathrm{NaBH} 4$ composite activated by $\mathrm{La}$ metal and $\mathrm{CoCl} 2$ salt in pure water. Journal of Rare Earths 30: 548-551.

9. Bardeen J (1947) Surface states and rectification at a metal semiconductor contact. Phys Rev 71: 717.

10. Liu S, Bao HB, Fan M, Chen D, Shu KY (2001) Study on hydrogen generation from AlLi/NaBH4 mixture in pure water for portable fuel cell. Adv Mater Res 239: 1058-1061.

11. Xing RU, Whitman WB (1994) Purification and characterization of the oxygen-sensitive acetohydroxy acid synthase from the archaebacterium Methanococcus aeolicus, J bacteriol 176: 1207-1213.

12. Paro L, Guglielmin M (2011) FINAL REPORT Handbook to establish alpine permafrost monitoring network. Italy. 